\title{
PENGARUH AKUPRESUR TERHADAP PENURUNAN MUAL DAN MUNTAH PADA IBU HAMIL DI PRAKTEK MANDIRI BIDAN SIDOARJO
}

\author{
${ }^{1}$ Nanik Handayani, ${ }^{2}$ R. Khairiyatul Afiyah \\ 1,2Dosen S1Keperawatan Fakultas Keperawatan dan Kebidanan \\ Universitas Nahdlatul Ulama Surabaya JI. Smea Surabaya \\ Email :nanik_handayani@unusa.ac.id, eer@unusa.ac.id
}

\begin{abstract}
ABSTRAK
Mual dan muntah ini merupakan hal yang fisiologis. Kondisi fisiologis ini akan berubah menjadi patologi apabila tidak dilakukan perawatan yang baik. Salah satu penatalaksanaan non farmakologis untuk mengurangi mual dan muntah bisa dengan akupresur. Tujuan dari penelitian ini adalah untuk mengetahui pengaruh akupresur terhadap penurunan mual dan muntah pada ibu hamil. Desain penelitian ini Quasy-Experiment, teknik pre post test control group design dengan populasinya seluruh ibu hamil yang mengalami mual dan muntah. Besar sampel 22 yaitu 11 orang diberi intervensi dan 11 orang sebagai kontrol diambil dengan teknik consecutive sampling. Instrumen pengumpulan data adalah kuesioner skor PUQE. Hasil penelitian pada kelompok intervensi sebelum dilakukan akupresur rata-rata yaitu 8,00 dan pada kelompok kontrol yaitu 7,00. Setelah dilakukan akupresur, kelompok intervensi rata-rata derajat mual dan muntah yaitu 5,00 dan pada kelompok kontrol yaitu 6,63. Terjadi penurunan pada kelompok intervensi yaitu 3,00 dan pada kelompok kontrol yaitu 0,36 . Hasil analisis uji statistik Independent $T$-test $\rho=0,010<\alpha=0,05$, sehingga $\mathrm{H}_{0}$ ditolak artinya akupresur berpengaruh terhadap penurunan mual dan muntah. Semakin rutin dilakukannya akupresur, maka keluhan mual dan muntah akan semakin menurun, sehingga dapat mencegah komplikasi pada ibu hamil.
\end{abstract}

Kata kunci: Akupresur, mual dan muntah

\begin{abstract}
Nausea and vomiting are physiological things. This physiological condition will turn into pathology if not done with good care. Pregnant women often ignore complaints of nausea and vomiting because it is considered normal in early pregnancy. The purpose of this study was to determine the side effect of acupressure on reducing nausea and vomiting in pregnant women. The design of this study is Quasy-Experiment, a pre-post test control group design technique with a population of all pregnant women who experience nausea and vomiting. Sample size 22 of which 11 people were given intervention and 11 people as controls were taken by consecutive sampling technique. The data collection instrument was the PUQE score questionnaire. The results of the study in the intervention group before acupressure were an average of 8.00 and in the control group was 7.00 . After acupressure, the intervention group had an average degree of nausea and vomiting of 5.00 and the control group was 6.63. There was a decrease in the intervention group that was 3,00 and in the control group that was 0.36 . The results of the statistical analysis of the Independent $T$ test $\rho=0.010<\alpha=0.05$, so that $\mathrm{HO}$ is rejected means that acupressure is effective against decreasing nausea and vomiting. The more routine acupressure is done, the complaints of nausea and vomiting will decrease, so as to prevent complications in pregnant women.
\end{abstract}

Keywords: Acupressure, nausea and vomiting 


\section{PENDAHULUAN}

Kehamilan yaitu pertumbuhan dan perkembangan dari intrauteri mulai sejak konsepsi sampai permulaan persalinan. Saat kehamilan bisa terjadi berbagai penyulit kehamilan yaitu mual dan muntah yang sering dialami pada ibu hamil, kondisi ini merupakan salah satu gejala paling awal kehamilan. Mual dan muntah saat kehamilan biasanya disebabkan oleh perubahan dalam sistem endokrin yang terjadi selama kehamilan. Penyebab utamanya karena tingginya fluktuasi kadar hCG (human chronic gonadotrophin). Pada saat mual atau muntah gestasional yang paling umum adalah pada usia kehamilan 12-16 minggu pertama, yang pada saat itu hCG mencapai kadar tertingginya (Tiran, 2009). Mual-mual biasanya terjadi di pagi hari, karena perut mengandung kumpulan asam gastrik yang diendapkan semalam (Nirwana, 2011).

Mual dan muntah ini merupakan hal yang fisiologis. Kondisi fisiologis ini akan berubah menjadi patologi apabila tidak dilakukan perawatan yang baik. Ibu hamil sering kali mengabaikan keluhan mual dan muntahnya karena dianggap sebagai hal yang normal diawal kehamilan. Jika mual dan muntah yang berlebihan pada ibu hamil tidak segera dilakukan penanganan yang baik dapat menyebabkan ibu hamil kekurangan gizi akhirnya janin tidak mendapatkan nutrisi adekuat yang dapat menyebabkan BBLR atau prematuritas.

Studi pendahuluan yg di lakukan pada tanggal 4 Juni 2019 dilakukan pengambilan data awal di BPS Nanik Sidoarjo diperoleh data ibu hamil pada bulan Januari sampai Mei 2019 sebanyak 100 orang yang mengalami mual dan muntah sebesar $65 \%$ orang.

Mual merupakan suatu perasaan yang sangat tidak enak di belakang tenggorokan dan epigastrium dan sering menyebabkan gejala muntah. Muntah merupakan suatu refleks yang menyebabkan dorongan ekspirasi isi lambung atau usus atau keduanya ke mulut. Saat produksi hCG mencapai puncaknya, diduga bahwa hormon plasenta inilah yang memicu mual dan muntah dengan bekerja pada CTZ (Chemoreseptor Trigger Zone). Muntah terjadi akibat perangsangan pada pusat muntah yang terletak di daerah postrema medula oblongata di dasar ventrikel ke empat. Muntah dapat dirangsang melalui jalur saraf aferen oleh rangsangan nervus vagus dan simpatis atau oleh rangsangan emetik yang menimbulkan muntah dengan aktivasi chemoreceptor trigger zone. Stimulus dalam CTZ dihantarkan ke pusat muntah yang menyebabkan otot dalam saluran gastrointestinal dan pernapasan memulai terjadinya mual dan muntah (Tiran, 2009)

Mual dan muntah dapat dikurangi dengan pemberian akupresur dengan menggunakan titik Neiguan (titik perikardium 6) yang berlokasi di antara tendon yaitu flexor carpi radialis dan otot palmaris longus, kirakira 3 jari di atas lipatan tangan. Efek stimulasi titik tersebut diyakini mampu meningkatkan pelepasan beta-endorphin di 
hipofise dan ACTH (Adrenocorticotropic Hormone) sepanjang Chemoreceptor Trigger Zone (CTZ) menghambat pusat muntah (BKTM, 2013).

Stimulasi pada median nerve di PC6 (Perikardium 6) atau titik akupresur neiguan telah banyak dipelajari untuk tujuan mengetahui keefektifan stimulasi titik tersebut dalam menurunkan mual dan muntah. Akupresur aman dilakukan sendiri walaupun belum pernah melakukan sebelumnya asalkan mengikuti petunjuk yang ada. Tidak ada efek samping, tidak menimbulkan bahaya karena tidak menggunakan bahan kimia sehingga diyakini tidak terdapat efek negatif pada ibu maupun bayinya (BKTM, 2013). Penelitian yang dilakukan Artika (2006) menjelaskan bahwa akupresur pada titik PC6 dapat menurunkan mual untuk kehamilan.

Penatalaksanaan mual dan muntah pada kehamilan terdiri atas farmakologi dan nonfarmakologi. Terapi farmakologi dilakukan dengan pemberian antiemetik, antihistamin, antikolinergik, dan kortikosteroid (Runiari, 2010). Sedangkan terapi nonfarmakologi merupakan jenis terapi keperawatan komplementer yang dapat digunakan untuk mengatasi mual adalah makan porsi kecil; hindari makanan berlemak, pedas, berbau tajam, dan berminyak; mengurangi stress, relaksasi aromaterapi, akupresur, akupuntur, refleksiologi, dan pengobatan herbal (Tiran, 2009).

\section{METODE}

Penelitian ini menggunakan penelitian Quasy-Experiment dengan pendekatan pre post test control group design. Rancangan ini berupaya untuk mengungkapkan hubungan sebab akibat dengan melibatkan kelompok kontrol disamping kelompok intervensi (Dharma, 2011). Dalam rancangan ini, kelompok intervensi diberikan perlakuan akupresur pada titik perikardium 6, sedangkan kelompok kontrol tidak diberikan perlakuan. Populasinya lbu hamil usia kehamilan trimester I-II yang mengalami mual dan muntah. Pada kelompok perlakuan dilakukan akupresur dengan menggunakan ibu jari pada titik perikardium 6 yang terletak 3 jari di atas pergelangan tangan yang segaris dengan jari tengah yang dilakukan 1 kali dalam sehari selama 2 menit. Akupresur ini dilakukan selama 7 hari,setelah itu diukur kembali tingkat mualnya kedua kelompok diawali dengan pre-test dan setelah pemberian perlakuan pada kelompok intervensi, dilakukan pengukuran kembali (post-test) derajat mual muntah dengan menggunakan Score Pregnancy Unique Quantification of Emesis and or Nausea Scoring System (PUQE)

\section{Tabel 1. Pregnancy Unique Quantification of Emesis and or Nausea Scoring} System

\begin{tabular}{|l|l|l|l|l|l|}
\hline $\begin{array}{l}\text { Pertany } \\
\text { aan 1 }\end{array}$ & \multicolumn{4}{|l}{$\begin{array}{l}\text { Dalam 12 jam terakhir, berapa } \\
\text { lama (jam) anda merasakan } \\
\text { mual? }\end{array}$} \\
\hline Respon & $\begin{array}{l}\text { Tidak } \\
\text { sama } \\
\text { sekali }\end{array}$ & $\begin{array}{l}1 \\
\text { jam/ } \\
\text { kura } \\
\text { ng }\end{array}$ & $\begin{array}{l}2-3 \\
\text { jam }\end{array}$ & $\begin{array}{l}4-6 \\
\text { Jam }\end{array}$ & $\begin{array}{l}>6 \\
\text { ja } \\
\mathrm{m}\end{array}$ \\
\hline Skor & 1 & 2 & 3 & 4 & 5 \\
\hline Pertany & Dalam & \multicolumn{1}{|l}{ 12 jam } & terakhir, \\
\hline
\end{tabular}




\begin{tabular}{|l|l|l|l|l|l|}
\hline aan 2 & \multicolumn{5}{|l|}{ pernahkah anda muntah? } \\
\hline Respon & $\begin{array}{l}\text { Tidak } \\
\text { sama } \\
\text { sekali }\end{array}$ & $\begin{array}{l}1-2 \\
\text { kali }\end{array}$ & $\begin{array}{l}3-4 \\
\text { kali }\end{array}$ & $\begin{array}{l}5-6 \\
\text { kali }\end{array}$ & $\begin{array}{l}\geq 7 \\
\text { kali }\end{array}$ \\
\hline Skor & 1 & 2 & 3 & 4 & 5 \\
\hline $\begin{array}{l}\text { Pertany } \\
\text { aan 3 }\end{array}$ & $\begin{array}{l}\text { Dalam 12 jam terakhir, berapa } \\
\text { kali anda merasa ada dorongan } \\
\text { dimuntahkan? }\end{array}$ \\
\hline Respon & $\begin{array}{l}\text { Tidak } \\
\text { sama } \\
\text { sekali }\end{array}$ & $\begin{array}{l}1-2 \\
\text { kali }\end{array}$ & $\begin{array}{l}3-4 \\
\text { kali }\end{array}$ & $\begin{array}{l}5-6 \\
\text { kali }\end{array}$ & kali \\
\hline Skor & 1 & 2 & 3 & 4 & 5 \\
\hline
\end{tabular}

Interpretasi Hasil:

PUQE skor antara 4-6: Derajat ringan

PUQE skor antara 7-12: Derajat sedang

PUQE skor $\geq 13$ : Derajat berat

- Pengujian sebab akibat dilakukan dengan cara membandingkan pre-test pada kelompok intervensi dengan kelompok kontrol, serta post-test pada kelompok intervensi dan kelompok kontrol.

Tabel 2. Rancang Penelitian QuasyExperiment

\begin{tabular}{llll}
\hline Subjek & Pra & Perlakuan & Pascates \\
\hline K-A & O & I & O1-A \\
K-B & O & - & O1-B \\
& Time 1 & Time 2 & Time 3
\end{tabular}

Keterangan:

K-A : Kelompok intervensi

K-B : Kelompok kontrol

O : Observasi mual dan muntah sebelum intervensi

I : Intervensi (Akupresur)

O1-A : Observasi mual dan muntah kelompok intervensi

O1-B : Observasi mual dan muntah kelompok kontrol

\section{HASIL PENELITIAN}

Tabel 3. Distribusi derajat mual dan muntah pada kelompok Intervensi dan kelompok kontrol sebelum dilakukan akupresur di Praktek Mandiri Bidan Sidoarjo 2019

\begin{tabular}{lcccccc}
\hline \multirow{2}{*}{ Kel } & \multicolumn{5}{c}{ Derajat Mual dan Muntah Pre } \\
\cline { 2 - 7 } & $\mathbf{N}$ & Mean & Median & Min & Max & SD \\
\hline Inter & 11 & 8,00 & 8,00 & 6,00 & 14,0 & 2,2 \\
Kontr & 11 & 7,00 & 7,00 & 6,00 & 9,00 & 1,18 \\
\hline Sumber: Data primer, Agust 2019 & &
\end{tabular}

Sumber: Data primer, Agust 2019

Berdasarkan tabel 3 menunjukkan derajat mual dan muntah dengan menggunakan skor PUQE, dimana sebelum dilakukan akupresur pada kelompok intervensi rata-rata didapatkan 8,00 yang merupakan derajat sedang dan nilai SD yaitu 2,21 . Sedangkan pada kelompok kontrol ratarata didapatkan 7,00 yang juga merupakan derajat sedang dan nilai SD yaitu 1,18.

Tabel 4. Distribusi derajat mual dan muntah pada kelompok Intervensi dan kelompok kontrol setelah dilakukan akupresur di Praktek Mandiri Bidan Sidoarjo 2019

\begin{tabular}{ll}
\hline \multirow{2}{*}{ KIp } & \multicolumn{2}{c}{ Derajat Mual dan Muntah Post } \\
\cline { 2 - 3 } & $\mathrm{N}$ Mean Median Min Max SD \\
\hline
\end{tabular}

$\begin{array}{llllll}\text { Intervensi } 11 & 5,00 & 5,00 & 4,00 & 8,00 & 1,40\end{array}$

$\begin{array}{lllllll}\text { Kontrol } & 11 & 6,63 & 7,00 & 5,00 & 8,00 & 0,92\end{array}$
$\rho$ value $\quad 010^{*}$

Sumber: Data primer, Agust 2019

Berdasarkan tabel 4 menunjukkan derajat mual dan muntah dengan menggunakan skor PUQE, dimana setelah dilakukan akupresur pada kelompok intervensi rata-rata didapatkan 5,00 yang merupakan derajat ringan dan nilai SD yaitu 1,40 . Sedangkan pada kelompok kontrol ratarata didapatkan 6,63 yang merupakan derajat ringan dan nilai SD yaitu 0,92.

Berdasarkan uji Independent T-test untuk membedakan derajat mual dan muntah dengan menggunakan skor PUQE, dimana setelah dilakukan tindakan akupresur pada kelompok intervensi dan kelompok kontrol 
didapatkan nilai $\rho=0,010$ dan nilai $\alpha=0,05$ berarti $\rho<\alpha$, artinya terdapat perbedaan yang bermakna skor PUQE antara kelompok intervensi dan kelompok kontrol setelah dilakukan tindakan akupresur.

Tabel 5. Distribusi Perbedaan derajat mual dan muntah pada kelompok intervensi dan kelompok kontrol sebelum dan setelah dilakukan akupresur di Praktek Mandiri Bidan Sidoarjo tahun 2019

\begin{tabular}{lllllllll}
\hline Jenis Test & \multicolumn{3}{c}{ Pre Test } & \multicolumn{3}{c}{ Post Test } & $\begin{array}{l}\boldsymbol{\rho} \\
\text { value }\end{array}$ \\
\hline Hasil & N & Mean SD & N Mean SD & \\
\hline $\begin{array}{l}\text { Kelompok } \\
\text { Intervensi }\end{array}$ & 11 & 8,00 & 2,21 & 11 & 5,00 & 1,40 &, $000^{*}$ \\
\hline $\begin{array}{l}\text { Kelompok } \\
\text { Kontrol }\end{array}$ & 11 & 7,00 & 1,18 & 11 & 6,63 &, 92 &, $104^{*}$ \\
\hline
\end{tabular}

Sumber: Data primer, Agust 2019

* Keterangan: Bermakna pada $\alpha<0,05$

Berdasarkan tabel 5 menunjukkan derajat mual dan muntah dengan menggunakan skor PUQE, dimana dari 11 responden kelompok intervensi didapatkan hasil rata-rata sebelum dilakukan tindakan akupresur yaitu 8,00 yang merupakan derajat sedang; dengan nilai SD yaitu 2,21. Sedangkan rata-rata setelah dilakukan tindakan akupresur pada kelompok intervensi yaitu 5,00 yang merupakan derajat ringan; dengan nilai SD yaitu 1,40. Dan dari 11 responden kelompok kontrol didapatkan hasil rata-rata pre test yaitu 7,00 yang merupakan derajat sedang dan nilai SD yaitu 1,18. Sedangkan rata rata post test 6,63 yang yg merupakan derajat ringan dan nilai SD yaitu 0,92.Pada kelompok kontrol juga terjadi penurunan tetapi tidak bermakna kerena hanya menurun nilai 0,37 yaitu dari 7.00 menjadi 6,63 sedangkan pada kelompok perlakuan terdapat penurunan yg bermakna yaitu 3,00 dari 8.00 menjadi 5.00 .

Berdasarkan uji Paired T-test pada kelompok intervensi didapatkan nilai $\rho=$ 0,000 dan nilai $\alpha=0,05$ berarti $\rho<\alpha$ maka $\mathrm{H}_{0}$ ditolak, artinya adanya pengaruh akupresur terhadap penurunan mual dan muntah pada ibu hamil trimester I-II di Praktek Mandiri Bidan Sidoarjo. Sedangkan pada kelompok kontrol didapatkan nilai $\rho=0,104$ dan nilai $\alpha$ $=0,05$ berarti $\rho>\alpha$ maka $\mathrm{H}_{0}$ diterima, yang berarti tidak ada pengaruh pada mual dan muntah kelompok kontrol karena tidak diberikan tindakan akupresur.

\section{PEMBAHASAN}

\section{Tingkat mual dan muntah sebelum dilakukan tindakan akupresur}

Pada saat kehamilan dapat mengalami berbagai masalah atau keluhan seperti halnya mual dan muntah yang sering dialami ibu hamil. Tingkat mual dan muntah pada setiap ibu hamil berbeda-beda. Mual dan muntah terjadi pada $60-80 \%$ primigravida dan $40-60 \%$ terjadi pada multigravida (Puriati, 2014). Pengukuran derajat mual dan muntah dengan menggunakan skor PUQE, di mana sebelum dilakukan akupresur pada kelompok intervensi rata-rata didapatkan 8,00 dan pada kelompok kontrol rata-rata didapatkan 7,00. Dilihat dari rata-rata PUQE pada kelompok intervensi dan kelompok kontrol menunjukkan derajat mual dan muntah yang dialami ibu hamil trimester I-II di PMB Sidoarjo merupakan derajat sedang. Derajat sedang adalah skor PUQE antara 7- 
12. Derajat sedang mual dan muntah pada ibu hamil ditandai dengan ibu tampak lemah, berat badan turun, keluhan mual dan muntah muncul setiap saat dimana ibu mengeluhkan mual dan muntahnya mengganggu dan ibu hamil akan merasakan dehidrasi ringan (Hidayati Ratna,2011)

\section{Derajat mual dan muntah setelah dilakukan tindakan akupresur}

Hasil penelitian pada ibu hamil trimester I-II di Praktek Mandiri Bidan Sidoarjo setelah diberikan tindakan akupresur mengalami penurunan rata-rata derajat mual dan muntah, terutama pada kelompok intervensi. Derajat mual dan muntah dengan menggunakan skor PUQE, di mana setelah dilakukan akupresur dari 11 responden kelompok intervensi rata-rata didapatkan 5,00 yang merupakan derajat ringan. Sedangkan dari 11 responden kelompok kontrol rata-rata didapatkan 6,63 merupakan derajat ringan. Pada ke 2 kelompok mengalami penurunan tingkat mual muntah yaitu pada kelompok perlakuan penurunannya bermakna yaitu menurun sebesar 3.00 sedangkan pada kelompok kontrol penurunannya tidak bermakna hanya terjadi skor PUQE 0,37.

\section{Pengaruh akupresur terhadap penurunan mual dan muntah pada ibu hamil trimester I-II di Praktik Mandiri Bidan Sidoarjo}

Akupresur merupakan penatalaksanaan non farmakologis yang dapat mengurangi mual dan muntah pada ibu hamil. Akupresur menekan titik-titik tertentu pada tubuh seseorang dengan jari, siku, atau alat tumpul semacamnya misalnya kayu kecil, bolpoin, dan sejenisnya (Murtie, 2013) Penelitian yang dilakukan De Aloysio dan Penacchioni (1992) melakukan uji silang dengan menggunakan akupresur unilateral, bilateral dan plasebo (melakukan akupresur tidak tepat pada titik PC6), masing-masing selama tiga hari dan ditemukan pengurangan mual dan muntah kehamilan sebesar $65-69 \%$ pada kelompok yang menggunakan akupresur dan pengurangan sebesar 29-31\% pada kelompok yang menggunakan plasebo (Tiran, 2009). Hasil penelitian pada kelompok intervensi setelah diberikan tindakan akupresur mengalami penurunan hasil ratarata derajat mual dan muntah yang signifikan yaitu yang mulanya 8,00 yang merupakan derajat sedang menjadi 5,00 yang merupakan derajat ringan. Dan dari 11 responden kelompok kontrol didapatkan hasil rata-rata sebelum dilakukan akupresur yaitu 7,00 yang merupakan derajat sedang. Sedangkan rata-rata setelah dilakukan tindakan akupresur pada kelompok kontrol yaitu 6,63 yang merupakan derajat ringan.

Berdasarkan uji Paired T-test pada kelompok intervensi didapatkan nilai $\rho=$ 0,000 dan nilai $\alpha=0,05$ berarti $\rho<\alpha$ maka $\mathrm{H}_{0}$ ditolak, artinya adanya pengaruh akupresur terhadap penurunan mual dan muntah pada ibu hamil trimester I-II di Praktik Mandiri Bidan Sidoarjo. Sedangkan pada kelompok kontrol didapatkan nilai $\rho=0,104$ dan nilai $\alpha$ $=0,05$ berarti $\rho>\alpha$ maka $\mathrm{H}_{0}$ diterima, yang berarti tidak ada pengaruh pada mual dan 
muntah kelompok kontrol karena tidak diberikan tindakan akupresur.

Akupresur dipercaya efektif untuk menurunkan mual muntah melalui efeknya terhadap peningkatan beta endorpin. Zat ini merupakan salah satu anti emetik alami yang mampu menurunkan stimulus muntah di CTZ (Chemoreseptor Trigger Zone) dan pusat muntah sehingga dapat menurunkan mual muntah (Syarif, 2009). Penekanan dilakukan dengan ujung jari. Penekanan pada saat awal harus dilakukan dengan lembut, kemudian secara bertahap kekuatan penekanan ditambah sampai terasa sensasi yang ringan, tetapi tidak sakit (Anggriawan,2013). Pada kelompok intervensi didapatkan hasil rata-rata selisih sebelum dan setelah dilakukan tindakan akupresur yaitu 3,00 dengan nilai SD yaitu 1,22. Dan dari 11 responden kelompok kontrol didapatkan hasil rata-rata selisih sebelum dan setelah tindakan akupresur yaitu 0,37 ; dengan nilai SD yaitu 0,67 . Berdasarkan uji Independent T-test untuk melihat adanya selisih skor PUQE sebelum dan setelah dilakukan tindakan akupresur pada kelompok intervensi dan kelompok kontrol didapatkan nilai $\rho=0,000$ dan nilai $\alpha$ $=0,05$ berarti $\rho<\alpha$, artinya terdapat selisih yang bermakna skor PUQE antara kelompok intervensi dan kelompok kontrol sebelum dan setelah dilakukan tindakan akupresur.

. Berdasarkan uji Independent T-test untuk membedakan derajat mual dan muntah dengan menggunakan skor PUQE, dimana setelah dilakukan tindakan akupresur pada kelompok intervensi dan kelompok kontrol didapatkan nilai $\rho=0,010$ dan nilai $\alpha=0,05$ berarti $\rho<\alpha$, artinya terdapat perbedaan yang bermakna skor PUQE antara kelompok intervensi dan kelompok kontrol setelah dilakukan tindakan akupresur.

\section{KESIMPULAN}

. Berdasarkan uji Independent T-test untuk membedakan derajat mual dan muntah dengan menggunakan skor PUQE, dimana setelah dilakukan tindakan akupresur pada kelompok intervensi dan kelompok kontrol didapatkan nilai $\rho=0,010$ dan nilai $\alpha=0,05$ berarti $\rho<\alpha$, artinya terdapat perbedaan yang bermakna skor PUQE antara kelompok intervensi dan kelompok kontrol setelah dilakukan tindakan akupresur.

Penekanan dilakukan dengan ujung jari. Penekanan pada saat awal harus dilakukan dengan lembut, kemudian secara bertahap kekuatan penekanan ditambah sampai terasa sensasi yang ringan, tetapi tidak sakit. Sehingga dalam penelitian ini disimpulkan bahwa, akupresur efektif untuk menurunkan mual muntah.

\section{DAFTAR PUSTAKA}

Artika, Putri. 2006. Pengaruh Akupresur Pada Titik Perikardium 6 Terhadap Penurunan Frekuensi Muntah Pada Primigravida Trimester Pertama Dengan Emesis Gravidarum. www.googlescholar.com, diunduh tanggal 10 juni 2019

Anggriawan, Feri. 2013. Tingkat Keberhasilan Masase Frirage Dan Akupresur Dalam Mengurangi Nyeri 
Dan Meningkatkan ROM (Range o Motion) Pada Pasien Cedera Bahu Di Klinik Sasana Husada Yogyakarta. www.googlescholar.com, diunduh tanggal 06 Juni 2019

Hidayati Ratna, 2011. Asuhan Keperawatan Pada Kehamilan Fisiologi dan patologis: Salemba Medika

Balai kesehatan tradisional masyarakat (BKTM) Makassar. 2013.Efektivitas Akupresur Terhadap Keluhan Mual Muntah pada lbu Hamil Trimester Pertama di Kota Makassar tahun 2013. Www.googlescholar.com, diunduh tanggal 29 Juni 2019

Dharma, Kelana Kusama. 2011. Metodologi Penelitian Keperawatan - Panduan Melaksanakan dan Menerapkan Hasil Penelitian. Jakarta: Trans Info Media

Murtie, Afin. 2013. Kupas Tuntas Pengobatan Tradisional: Pemahaman, Manfaat, Teknik, \& Praktik. Yogyakarta: Trans Idea

Nirwana, Ade Benih. 2011. Kapita Selekta Kehamilan. Yogyakarta: Nuha Medika

Puriati, Ruri et al. 2014. Hubungan paritas dan umur ibu dengan Kejadian hiperemesis gravidarum di RSUD Adjidarmo rangkasbitung tahun 2011. www.googlescholar.com, diunduh tanggal 1 Juli 2019

Runiari, Nengah. 2010. Asuhan Keperawatan pada Klien dengan Hiperemesis Gravidarum: Penerapan Konsep dan Teori Keperawatan. Jakarta: Salemba Medika.

Syarif, Hilman. 2009. Pengaruh Terapi Akupresur Terhadap Muak Muntah Akut Akibat Kemoterapi Pada Pasien Kanker: A Randomized Clinical Trial. www.googlescholar.com, diunduh tanggal 20 Juli 2019

Tiran, Denise. 2009. Mual dan Muntah Kehamilan. Jakarta: EGC 